\title{
Slide tracheobronchoplasty in an infant
}

Emmanuel Le Bret, MD, PhD, ${ }^{\text {a }}$ Eréa Noel Garabédian, $M D,{ }^{b}$ Natacha Teissier, $M D,{ }^{b}$ Emre Belli, MD, ${ }^{a}$
Noureddine Gharbi, MD, ${ }^{\text {a }}$ Jacqueline Bruniaux, $M D,{ }^{a}$ Régine Roussin, $M D,{ }^{a}$ Anne Sigal-Cinqualbre, $M D,{ }^{c}$ and Alain Serraf, MD, PhD

See related brief communication on page 179 .

I nitially described by Tsang and colleagues in $1989,{ }^{1}$ slide tracheoplasty has become the technique of choice to treat longsegment tracheal stenosis. ${ }^{2}$ The advantages of this technique are avoidance of graft materials, avoidance of tension on the sutures, satisfactory enlargement of the trachea, and avoidance of impairment of the anatomic and functional growth of the trachea. ${ }^{3}$ The association of tracheal resection and slide tracheoplasty was recently reported by our team ${ }^{4}$ as a possible treatment for an infant presenting with tracheal hypoplasia associated with partial critical stenosis. However, surgical management of a tracheal hypoplasia extending down to the bronchus is still challenging.

We report a variant of the slide tracheoplasty that allowed us to treat this difficult case.

\section{Case}

\section{Patient and Anatomic Lesion}

A 3-month-old infant weighing $3.5 \mathrm{~kg}$ was primarily referred for tracheal hypoplasia. The child had been intubated for 1 month in his birth country. The infant was admitted to our department with tracheal septic contamination. Endoscopy and computed tomography scan analysis showed a severe tracheal hypoplasia starting at the middle of the trachea and extending to the main bronchi and carina. After administering intense anti-biotherapy to the infant for 1 week, we decided to perform surgery.

\section{Surgical Technique}

A transverse cervical incision combined with a median sternotomy was performed. Dissection of the entire trachea was accomplished. Care was taken to respect the vascularization of the lower part of the trachea, carina, and main bronchi, but the upper trachea was

From the Service des cardiopathies congénitales, Centre chirurgical Marie Lannelongue, Le Plessis Robinson, France; ${ }^{a}$ Département d'ORL pédiatrique, Hôpital d'enfants Armand Trousseau, Université Paris VI, Paris, France; 'b and Département d'imagerie médicale, Scanner, Centre chirurgical Marie Lannelongue, Le Plessis Robinson, France. ${ }^{c}$

Received for publication Dec 16, 2005; accepted for publication Jan 13, 2006.

Address for reprints: Emmanuel Le Bret, MD, PhD, Service des Cardiopathies Congénitales, Centre Chirurgical Marie Lannelongue, 133 avenue de la Résistance, 92350 Le Plessis Robinson, France (E-mail: e.lebret@ccml.fr).

J Thorac Cardiovasc Surg 2006;132:181-3

0022-5223/ $\$ 32.00$

Copyright $\odot 2006$ by The American Association for Thoracic Surgery doi:10.1016/j.jtcvs.2006.02.054 circumferentially dissected. The patient was then heparinized, and a normothermic cardiopulmonary bypass was established between the right atrium and the aorta. Dissection of the carina and main bronchi was then completed. The main bronchi were freed anteriorly right to their division, respecting their posterior walls. The trachea was first transversally transected at the junction between the lower third and the upper two thirds of the hypoplasia (Figure 1). The distal end of the trachea was longitudinally sectioned along its anterior wall down to the carina. The carina and the origin of the

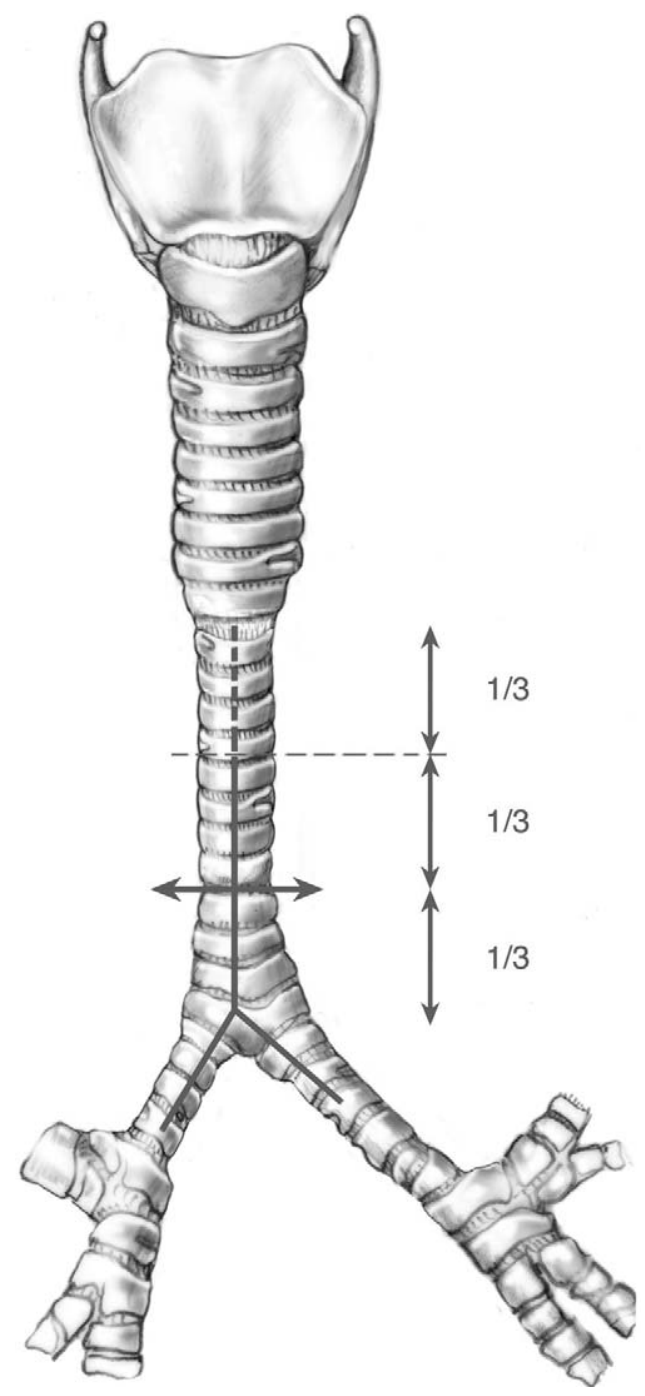

Figure 1. Hypoplasia started at the middle of the trachea and extended to the main bronchi. 

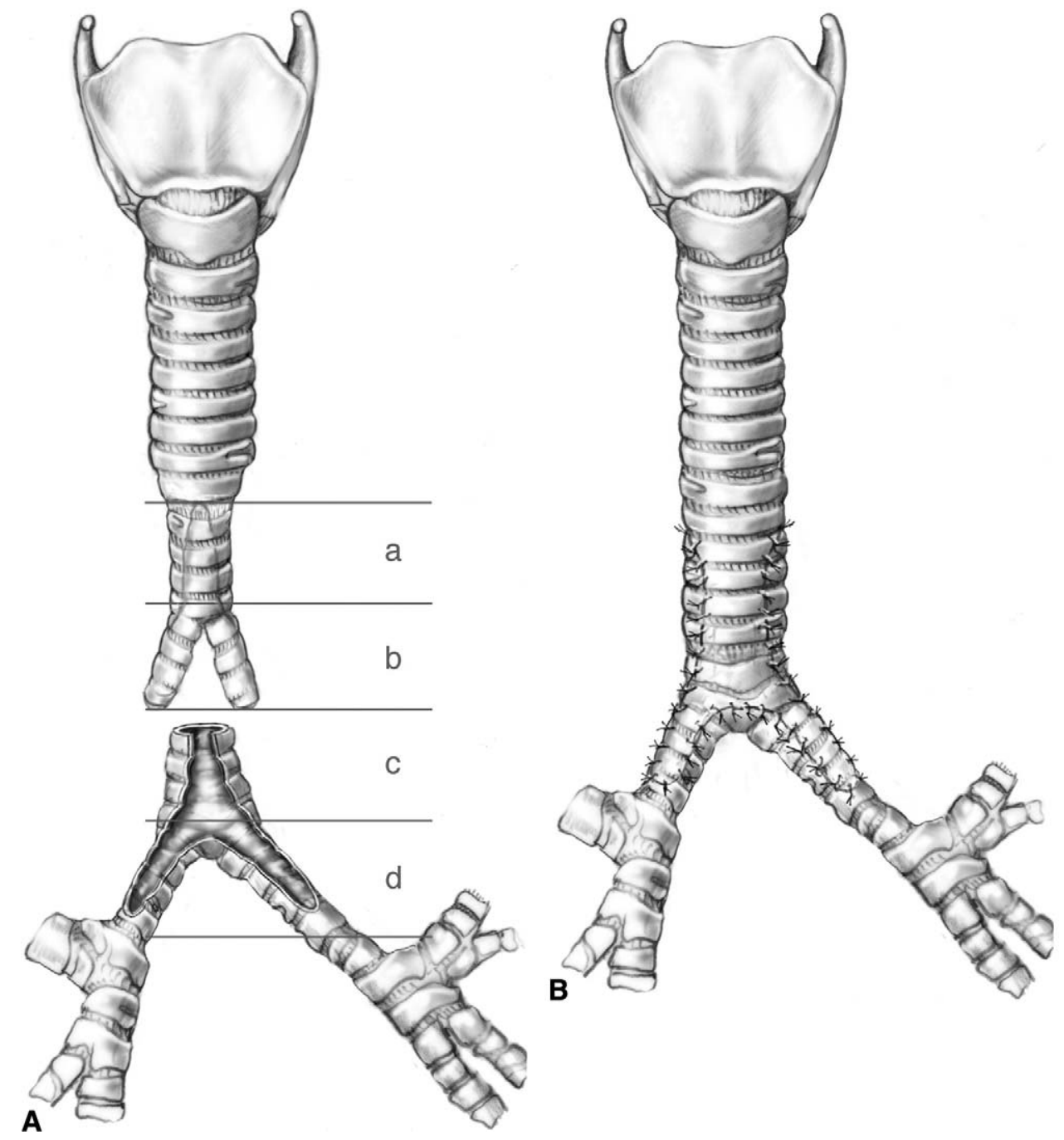

Figure 2. A and B, Trachea and main bronchi were opened for enlargement.

main bronchi were opened superoanteriorly (Figure 2, A). The proximal end of the trachea was also longitudinally split along its posterior wall, along the entire length of the hypoplasia. The anterior wall of the proximal end of the trachea was also split half-length. The tracheal walls were trimmed to make a gently sloping autologous tracheal patch. The anastomosis was performed with interrupted sutures of 5-0 and 6-0 Polydioxanone suture (PDS, Ethicon Inc, Somerville, NJ). Suturing was initiated proximally between the inferior tongue of the trachea and the normal trachea. The final sutures were placed at the distal end of the tongue of the anterior wall of the trachea, which was sutured down to the anterosuperior part of the main bronchi and carina (Figure 2, $B)$. The endotracheal tube was replaced, ventilation was reestablished, and the patient was weaned from cardiopulmonary bypass.

\section{Follow-up}

The patient was extubated on the ninth postoperative day under bronchoscopic control. A distal bronchomalacia was the cause of the delayed extubation. At 6 months, the child was doing well; the bronchoscopic examination showed a good tracheal, carinal, and bronchial repair without granulomatous tissue.

\section{Comments}

The slide tracheobronchoplasty is the latest extension of the slide tracheoplasty technique. This modification was proposed by Grillo in $2004^{5}$ for patients in whom significant stenosis is present in the proximal main bronchi.

In this particular case, it was important to choose the option before incising the trachea. Because the point of transverse division of the hypoplastic segment is below the midpoint of the tracheal stenosis, it also has to provide the necessary length for slide bronchoplasty. In this case, the section of the trachea was performed in the lower third of the hypoplastic zone, and half of the upper hypoplastic segment was used to enlarge the anterior part of the main bronchi origin. If a longer segment of the bronchi were 
to be enlarged, a longer segment of the trachea would be necessary, and the primary section of the trachea would have to be much lower.

Care must be taken to connect the 2 tongues of the trachea, which must fit perfectly to the anterior part of the bronchi with no tension and no disrotation.

\section{Conclusion}

Extended slide tracheoplasties enable successful tracheal reconstruction even when main bronchi are involved in the hypoplasia. Use of the patient's own tracheal tissues and avoidance of foreign materials should enable good tracheobronchial growth in the same way that slide tracheoplasty enables good tracheal growth.

\section{References}

1. Tsang V, Murday A, Gilbe C, Goldstraw P. Slide tracheoplasty for congenital funnel shaped tracheal stenosis. Ann Thorac Surg. 1989;48:632-5.

2. Lang FJW, Hurni M, Monnier P. Long segment congenital tracheal stenosis: treatment by slide tracheoplasty. J Pediatr Surg. 1999;34:1216-22.

3. Kutlu CA, Goldstraw P. Slide tracheoplasty for congenital funnel shaped tracheal stenosis (a 9-year follow-up of the first case). Eur J Cardiothorac Surg. 1999;16:98-9.

4. Garabedian EN, Le Bret E, Corre A, Roger G, Pineau E, Bourel P. Tracheal resection associated with slide tracheoplasty for long segment congenital tracheal stenosis involving the carina. J Thorac Cardiovasc Surg. 2001;121:393-5.

5. Grillo HC (ed). Repair of congenital tracheal lesions. In: Grillo HC, ed. Surgery of the trachea and bronchi. Hamilton, Ontario, Canada: BC Decker Inc; 2004. p. 655-74

\section{Methicillin-resistant Staphylococcus aureus infection causing Pancoast syndrome}

Hon Chi Suen, MD, ${ }^{a}$ Richard A. Summa, MD, ${ }^{b}$ Alexander Babich, MD, ${ }^{c}$ Edwin C. Ernst, MD, ${ }^{d}$ Phillip Zinser, MD, ${ }^{e}$ Wilfrido C. Feliciano, MD, ${ }^{f}$ and John H. Rice, MD, ${ }^{g}$ St Louis, MO

I nfectious causes of Pancoast syndrome have been described. We present the first case report of methicillin-resistant Staphylococcus aureus (MRSA) pulmonary abscess with osteomyelitis of the first rib mimicking a Pancoast tumor in a non-immunocompromised young man.

\section{Clinical Summary}

A 41-year-old African American man reported right shoulder pain radiating down the right arm for 3 months. Examination revealed a well-built person with no positive physical findings. Chest radiography was unremarkable, but a computed tomography chest showed a 3-cm mass abutting the right first rib, right internal thoracic artery, and right brachiocephalic vein (Figure 1). There was no enlarged mediastinal lymph node. Positron emission tomography scan showed intense activity in the mass. Bone scan showed increased activity in the right first rib suggesting lytic changes. Magnetic resonance imaging of the chest confirmed chest wall invasion without vascular or brachial plexus involvement. The findings were indicative of a Pancoast tu-

From the a Departments of Cardiothoracic Surgery, ${ }^{\mathrm{b} P u l m o n o l o g y, ~}{ }^{\mathrm{c} P a t h o l-}$ ogy, ${ }^{\mathrm{d}}$ Radiology, ${ }^{\mathrm{e}}$ Infectious Disease, ${ }^{\mathrm{f}}$ Plastic Surgery, and ${ }^{\mathrm{g}}$ Internal Medicine, DePaul Health Center, St Louis, MO.

Received for publication Jan 18, 2006; accepted for publication Feb 8, 2006.

Address for reprints: Hon Chi Suen, MD, Cardiothoracic Surgery Associates, SC, 12B Park Place, Swansea, IL 62226 (E-mail address: HSUEN@ earthlink.net)

J Thorac Cardiovasc Surg 2006;132:183-4

$0022-5223 / \$ 32.00$

Copyright $\odot 2006$ by The American Association for Thoracic Surgery doi:10.1016/j.jtcvs.2006.02.023 mor. The initial plan was to confirm malignancy by needle biopsy and then treat the patient with neoadjuvant chemoirradiation followed by surgery. However, two needle biopsies were nondiagnostic.

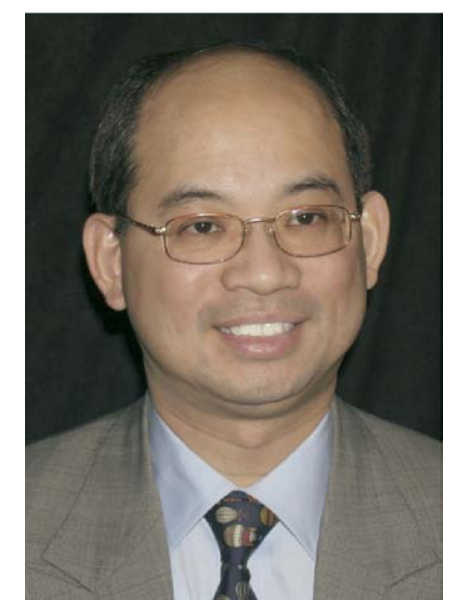

Dr Suen

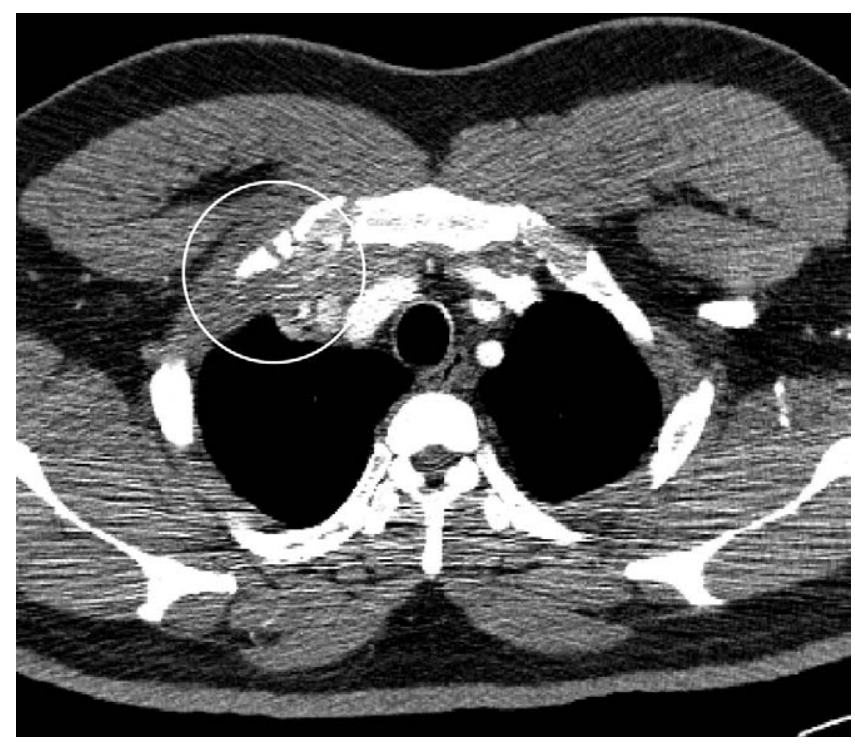

Figure 1. Computed tomography of the chest showed a 3-cm mass abutting the right first rib, right internal thoracic artery, and right brachiocephalic vein. 